\title{
Granular Layer Neurons Control Cerebellar Neurovascular Coupling Through an NMDA Receptor/NO-Dependent System
}

\author{
- Lisa Mapelli, ${ }^{1,4 *}$ Giuseppe Gagliano, ${ }^{1 *} \oplus^{-T e r e s a}$ Soda, ${ }^{1,4}$ Umberto Laforenza, ${ }^{2}$-Francesco Moccia, ${ }^{3 \dagger}$ \\ and Egidio U. D'Angelo ${ }^{1,5 \dagger}$ \\ ${ }^{1}$ Department of Brain and Behavioral Sciences, ${ }^{2}$ Department of Molecular Medicine, and ${ }^{3}$ Department of Biology and Biotechnology L. Spallanzani, \\ University of Pavia, 27100 Pavia, Italy, ${ }^{4}$ Museo Storico della Fisica e Centro Studi e Ricerche Enrico Fermi, 00184 Rome, Italy, and ${ }^{5}$ Brain Connectivity \\ Center, C. Mondino National Neurological Institute, 27100 Pavia, Italy
}

Neurovascular coupling (NVC) is the process whereby neuronal activity controls blood vessel diameter. In the cerebellum, the molecular layer is regarded as the main NVC determinant. However, the granular layer is a region with variable metabolic demand caused by large activity fluctuations that shows a prominent expression of NMDA receptors (NMDARs) and nitric oxide synthase (NOS) and is therefore much more suitable for effective NVC. Here, we show, in the granular layer of acute rat cerebellar slices, that capillary diameter changes rapidly after mossy fiber stimulation. Vasodilation required neuronal NMDARs and NOS stimulation and subsequent guanylyl cyclase activation that probably occurred in pericytes. Vasoconstriction required metabotropic glutamate receptors and CYP $\omega$-hydroxylase, the enzyme regulating 20 -hydroxyeicosatetraenoic acid production. Therefore, granular layer capillaries are controlled by the balance between vasodilating and vasoconstricting systems that could finely tune local blood flow depending on neuronal activity changes at the cerebellar input stage.

Key words: capillaries; cerebellum; granule cells; neurovascular coupling; nitric oxide; NMDA receptor

\section{Significance Statement}

The neuronal circuitry and the biochemical pathways that control local blood flow supply in the cerebellum are unclear. This is surprising given the emerging role played by this brain structure, not only in motor behavior, but also in cognitive functions. Although previous studies focused on the molecular layer, here, we shift attention onto the mossy fiber granule cell (GrC) relay. We demonstrate that $\mathrm{GrC}$ activity causes a robust vasodilation in nearby capillaries via the NMDA receptors-neuronal nitric oxide synthase signaling pathway. At the same time, metabotropic glutamate receptors mediate 20-hydroxyeicosatetraenoic aciddependent vasoconstriction. These results reveal a complex signaling network that hints for the first time at the granular layer as a major determinant of cerebellar blood-oxygen-level-dependent signals.

\section{Introduction}

Neurovascular coupling (NVC) is the mechanism whereby changes in regional cerebral blood flow $(\mathrm{CBF})$ ensure the proper supply of oxygen and glucose in response to local neuronal activ-

\footnotetext{
Received June 23, 2016; revised Nov. 28, 2016; accepted Dec. 3, 2016.

Author contributions: F.M. and E.U.D. designed research; L.M., G.G., and U.L. performed research; L.M., G.G., and

T.S. analyzed data; L.M., F.M., and E.U.D. wrote the paper.

This work was supported by the European Union Human Brain Project [Grant HBP-604102 to E.D. and Fermi Grant 13(14) to E.D. and L.M.].

The authors declare no competing financial interests.

*L.M. and G.G. contributed equally to this work.

${ }^{\dagger}$ F.M. and E.U.D. are cosenior authors.

Correspondence should be addressed to Prof. Egidio U. D'Angelo, Department of Brain and Behavioral Sciences, University of Pavia, via Forlanini 6, 27100 Pavia, Italy. E-mail: dangelo@unipv.it.

DOI:10.1523/JNEUROSCI.2025-16.2016

Copyright $\odot 2017$ the authors $\quad 0270-6474 / 17 / 371340-12 \$ 15.00 / 0$
}

ity. This coupling between neuronal activity and the hemodynamic response generates the blood-oxygen-level-dependent (BOLD) signals used in fMRI (Iadecola, 2004). Therefore, determining the cellular and molecular underpinnings of NVC is essential, not just to understanding local blood flow regulation, but also in interpreting BOLD signals as a function of brain activity (Logothetis, 2008; Hillman, 2014).

The vascular tone is determined by the balance between competing vasoconstrictor and vasodilator factors. The nonconventional gaseous neurotransmitter nitric oxide (NO) contributes to vasodilation in several brain regions (Iadecola, 2004). NO production is triggered by NMDA receptor (NMDAR)-mediated $\mathrm{Ca}^{2+}$ inflow, which activates the $\mathrm{Ca}^{2+}$-dependent neuronal isoform of NO synthase (nNOS) (Attwell et al., 2010). In the cerebellum, the mossy fiber (MF)-granule cell ( $\mathrm{GrC}$ ) relay receives 
and processes the incoming afferent signals before relaying them to Purkinje cells, which constitute the sole output of the cerebellar cortex, through GrC parallel fibers (Mapelli et al., 2015). So far, attention has mostly been given to the role of nNOS revealed in parallel fibers (Bouvier et al., 2016) and molecular layer interneurons such as stellate cells and basket cells. Because nNOS is absent in Purkinje cells, parallel fibers and molecular layer interneurons have long been regarded as the main sources of $\mathrm{NO}$ for cerebellar NVC (Akgören et al., 1994; Yang et al., 1999). Conversely, the role played by $\mathrm{GrCs}$ in the regulation of local microvessels has been neglected. This is surprising for several reasons. First, the cerebellum granular layer has the highest expression of NMDARs (Monaghan and Anderson, 1991) and nNOS (Snyder, 1992; Southam et al., 1992) in the whole brain (and the nNOS present in parallel fibers belongs to GrCs). The reason for this high expression is only partly understood, although GrC-derived NO has been implicated in long-term synaptic plasticity (Maffei et al., 2003; D’Angelo, 2014). Second, GrCs are the most abundant brain neurons $\left(3-7 \times 10^{6} / \mathrm{mm}^{3}\right)$ and recent calculations suggest that they are the most energyconsuming elements in the cerebellum (Howarth et al., 2010). Third, once stimulated, MFs release glutamate that excites postsynaptic GrCs by activating NMDA and non-NMDARs (D'Angelo et al., 1999). NMDAR-mediated $\mathrm{Ca}^{2+}$ entry activates nNOS and leads to NO production (Maffei et al., 2003). Interestingly, the first demonstration at all that NO could act as a vasodilator in the brain was provided in seminal papers showing that cerebellar GrC suspensions released NO upon NMDA stimulation, thereby causing smooth muscle relaxation through a guanylyl-cyclase-dependent mechanism (Garthwaite and Garthwaite, 1987; Garthwaite et al., 1989). Reasonably, GrC-released NO could induce vasodilation in adjacent microvessels, thereby increasing local CBF. Fourth, granule cells are almost silent at rest and respond to incoming MF bursts (Chadderton et al., 2004; Rancz et al., 2007; Powell et al., 2015) generating dense activity clusters (Diwakar et al., 2011), thereby implying a local neurongated mechanisms for blood flow regulation. Finally, whereas $\mathrm{NO}$ only plays a permissive role in the neocortex, NO is the primary mediator of the increase in CBF occurring in response to cerebellar activation (Akgören et al., 1994; Yang and Iadecola, 1997). This would, however, be hard to explain by considering the molecular layer only, where NVC is dissociated from the spiking activity of Purkinje cells, which cannot produce NO (Mathiesen et al., 1998; Caesar et al., 2003; Thomsen et al., 2004). Despite this body of evidence, the relationship between $\mathrm{GrCs}$ and CBF has hitherto remained undetermined.

Therefore, we investigated whether and how synaptic activity was coupled to vascular motility in the granular layer by combining bright-field microscopy and fast NO imaging in acute cerebellar slices in rats. We focused on capillaries because stringent evidence has been provided demonstrating that they aid arterioles in initiating functional imaging signals in the cerebellum (Hall et al., 2014).

\section{Materials and Methods}

Preparation of acute cerebellar slices. Acute rat cerebellar slices were obtained as reported previously (D'Angelo et al., 1995; Armano et al., 2000; Mapelli et al., 2009). Briefly, 17- to 23-d-old Wistar rats of both sexes were anesthetized with halothane (Sigma-Aldrich) and killed by decapitation. Parasagittal 220- $\mu \mathrm{m}$-thick acute slices were cut from the cerebellar vermis in cold Krebs solution and recovered for at least $1 \mathrm{~h}$ before being transferred to a $2 \mathrm{ml}$ recording chamber mounted on the stage of an upright microscope (Slicescope; Scientifica). The preparations were perfused with Krebs solution
( $2 \mathrm{ml} / \mathrm{min}$ ) and maintained at $32^{\circ} \mathrm{C}$ with a Peltier feedback device (TC-324B; Warner Instruments). Krebs solution for slice cutting and recovery contained the following (in mM): $120 \mathrm{NaCl}, 2 \mathrm{KCl}, 1.2 \mathrm{MgSO}_{4}, 26 \mathrm{NaHCO}_{3}, 1.2$ $\mathrm{KH}_{2} \mathrm{PO}_{4}, 2 \mathrm{CaCl}_{2}$, and 11 glucose and was equilibrated with $95 \% \mathrm{O}_{2} / 5 \%$ $\mathrm{CO}_{2}, \mathrm{pH}$ 7.4. When specified, slices were preincubated for $1 \mathrm{~h}$ in $75 \mathrm{nM}$ $\mathrm{U} 46619$ or $200 \mu \mathrm{M} \mathrm{L}-\mathrm{N}^{\mathrm{G}}$-Nitroarginine methyl ester (L-NAME). When specified, $100 \mu \mathrm{M}$ D-APV + $50 \mu \mathrm{M} 7 \mathrm{ClKyn}$ or $10 \mu \mathrm{M} 1 \mathrm{H}-[1,2,4]$ oxadiazolo[4,3a] quinoxalin-1-one (ODQ) or $500 \mu \mathrm{M} \alpha$-methyl-4-carboxyphenylglycine $(\mathrm{MCPG})+300 \mu \mathrm{M}(\mathrm{RS})-\alpha$-cyclopropyl-4-phosphonophenylglycine (CPPG) were added to the extracellular solution.

All drugs were obtained from Sigma-Aldrich except U46619, L-NAME, D-APV, 7-Cl-Kyn, MCPG, CPPG, and ODQ, which were obtained from Abcam.

All experimental protocols were conducted in accordance with international guidelines from the European Union Directive 2010/63/EU on the ethical use of animals and were approved by the local ethical committee of the University of Pavia, Italy.

Immunofluorescence. Immunofluorescence of pericytes and capillaries in cerebellar slices was performed as described previously (Mishra et al., 2014). In brief, $220 \mu \mathrm{m}$ slices were fixed with freshly prepared $4 \%$ paraformaldehyde in PBS for $25 \mathrm{~min}$ in a Petri dish. Slices were washed 3 times and then permeabilized and blocked with a solution containing $5 \%$ Triton X-100, 10\% BSA in PBS overnight at $4^{\circ} \mathrm{C}$. Slices were incubated for $1 \mathrm{~d}$ at room temperature on a rotary shaker with primary antibodies diluted in PBS. Rabbit anti-NG2 chondroitin sulfate proteoglycan (Millipore, catalog \#AB5320, 1:200 dilution) was used to stain pericytes and FITC-isolectin B4 (Sigma-Aldrich, catalog \#L2895; a stock solution of 2 $\mathrm{mg} / \mathrm{ml}$ FITC-IB4 in $\mathrm{H}_{2} \mathrm{O}$ was diluted 1:200 in PBS) was used to stain blood vessels. To prevent photobleaching, Petri dishes were covered with aluminum foil. After 315 min washes with PBS, slices were incubated for $4 \mathrm{~h}$ at room temperature with fluorescent secondary antibody at a 1:500 dilution (Jackson ImmunoResearch catalog \#111-295-045 rhodamine red-X-AffiniPure goat anti-rabbit IgG). Slices were then washed three times for 15 min with PBS, mounted on microscope slides, ProLong Gold antifade reagent with DAPI (Invitrogen), and coverslips affixed. Slides were examined with a TCS SP5 II confocal microscopy system (Leica Microsystems) equipped with a DM IRBE inverted microscope (Leica Microsystems). Images were acquired with $20 \times, 40 \times$, or $63 \times$ objectives and visualized by LAS AF Lite software (Leica Microsystems Application Suite Advanced Fluorescence Lite version 2.6.0). Negative controls were performed by incubating slices with nonimmune serum.

Time-lapse bright-field imaging of granular layer capillaries dynamics. Acute parasagittal cerebellar slices were prepared as described previously. Microvessels in the granular layer were identified using a $60 \times$ objective (LumPlanFl $60 \times / 0.90 \mathrm{~W}$; Olympus) during bright-field visual inspection of the granular layer. Only vessels with an internal diameter $<10 \mu \mathrm{m}$ were accepted for the experiments. In all cases, slices were preincubated in a $75 \mathrm{~nm}$ concentration of the thromboxane agonist U46619 to avoid vessel relaxation due to the slicing procedure and were typical of ex vivo conditions, in which vessels lack intraluminal flow and pressure. Only one capillary per slice was used for experiments. We focused on capillary sections covered by at least one to two pericytes sitting on the abluminal wall. Pericytes were identified by their large soma usually emitting two primary projections along the vessel (Hamilton et al., 2010; see Fig. 2Bc). In each slice, a suitable capillary was identified and the objective focus was finely adjusted to determine the capillary diameter near pericytes, where vasoconstriction was most evident featuring a sphincter-like structure (Peppiatt et al., 2006; Fernández-Klett et al., 2010). The focal plane on which the capillary diameter was measured did not necessarily coincide with that of the pericytes, which therefore appear blurred in some images.

Brain slices have long been used to unveil the molecular pathways and the local microcircuitry involved in NVC (Peppiatt et al., 2006; Rancillac et al., 2006; Hall et al., 2014), but we reasoned that it was physiologically more relevant to assess the effect of synaptic stimulation rather than administrating a neurotransmitter (e.g., glutamate) directly, which could cause the unspecific activation of the whole neuronal circuit. MF stimulation was performed using a bipolar tungsten electrode (Warner Instruments) and consisted of $12-15 \mathrm{~V}$ stimuli delivered at $50 \mathrm{~Hz}$ for $35 \mathrm{~s}$. This 
stimulation protocol allowed vessel tone (either vasodilation or vasoconstriction) to attain near-maximal changes (e.g., observed between 2 and $30 \mathrm{~s}$ in the case of vasodilation; see Fig. 2B). The stimulation frequency of $50 \mathrm{~Hz}$ was chosen to activate NMDARs and calcium entry efficiently (D’Angelo et al., 1995; D'Errico et al., 2009). The consequent granular layer responses are likely to span over distances longer than $\sim 200 \mu \mathrm{m}$ from the stimulating electrode, where vessel responses were detected, as suggested by previous observations using voltage-sensitive dye imaging (Prestori et al., 2013). Time-lapse bright-field acquisitions of capillaries dynamics were obtained through a CCD camera (DMK41BU; Imaging Source) using IC-capture 2.1 software (Imaging Source), acquiring images either every $30 \mathrm{~s}$ (for $>1 \mathrm{~h}$ acquisition of basal U46619 or L-NAME effects on vessel tone) or every $1 \mathrm{~s}$ (for acquisitions during and after MF stimulation) with an exposure time of $5 \mathrm{~ms}$. The analysis of capillary inner diameter changes was made offline using the ImageJ measuring tool by manually placing the measurement line perpendicular to the vessel at the location where maximal effect was detected visually, as described previously (Hall et al., 2014). The average distance from the stimulating electrode of the vessels used in the analysis was $191 \pm 10 \mu \mathrm{m}$ $(n=50)$. The percentage change in capillary resistance and in blood flow caused by capillary dilation was calculated as described previously (Peppiatt et al., 2006; Hall et al., 2014). Statistical comparisons were performed using the Student's $t$ test (paired or unpaired depending on the applicability). Statistical significance was assessed when $p<0.05$. Data are reported as mean \pm SEM.

Contribution of capillary vasodilation to the increase in CBF. Recent work has clearly shown that capillary vasorelaxation initiates before arteriole dilation in the molecular layer of the cerebellum (Peppiatt et al., 2006; Hall et al., 2014; Mishra et al., 2014). The percentage increase in granular layer blood flow produced by capillary vasodilation was evaluated by following procedures described previously (Peppiatt et al., 2006; Hall et al., 2014). Peppiatt et al. based their calculations on a mathematical model that attributes to the whole capillary bed a resistance that is $45 \%$ of the resistance in precapillary arterioles and arteries (Lu et al., 2004; Peppiatt et al., 2006). For instance, in slices superfused with U46619, MF stimulation causes an initial increase in capillary diameter by $5 \%$. According to the Poiseuille's law ( $r=8$ $\left.\eta \mathrm{l} / \pi \mathrm{r}^{4}\right)$, this reduces capillary resistance by $17 \%$ and therefore decreases the total flow resistance by $5.5 \%$ (if we assume that the resistance ratio for capillaries is 45:100). It turns out that the blood flow will increase by $5.8 \%[(100 /(100-5.5)) * 100$; for details, see Peppiatt et al., 2006].

DAF-FM imaging in cerebellar slices. Cerebellar slices were obtained as described above. After $1 \mathrm{~h}$ of recovery from the slicing procedure, the slices were transferred to a continuously oxygenating recovery with Krebs solution added with $75 \mathrm{~nm} \mathrm{U} 46619$ and $12 \mu \mathrm{M}$ 4-amino-5methylamino-2', $7^{\prime}$-difluorofluorescein (DAF-FM; Invitrogen) for 40 min. After the staining, the slices were transferred to a recovery chamber with Krebs solution and U46619 for at least 20 min before starting the experiment. DAF-FM fluorescence was detected using a MICAM01 CCD camera (Brainvision) controlled by the Brainvision software for remote acquisition and shuttering. With the $20 \times$ objective magnification (Olympus XLUMPlanFl $20 \times / 0.95 \mathrm{~W}$ ), with a detection matrix of $88 \times$ 60 pixels, each pixel corresponded to $4.5 \times 4.5 \mu \mathrm{m}$, which resulted in a field of view of $\sim 400 \times 270 \mu \mathrm{m}$. It should be noted that this fluorescence camera is pixelated and allows the detection of fluorescence responses with high spatial resolution. The fluorescence light (source MHAB150W; Moritex) was delivered to the tissue through an excitation filter $(495 / 20 \mathrm{~nm})$ and collected by the camera through a dichroic filter $(515$ $\mathrm{nm} \mathrm{LP})$ and an emission filter $(540 / 30 \mathrm{~nm})$. The acquisition rate was set at $15 \mathrm{~ms}$ ( 339 frames for $\sim 5 \mathrm{~s}$ recording). To obtain a better signal-tonoise ratio, up to 4 acquisitions were averaged in the presence and absence of $50 \mathrm{~Hz} 4 \mathrm{~s}$ stimulation on MFs. The average fluorescence signal in absence of MF stimulation was subtracted from the average fluorescence signal during MF stimulation (see Fig. 4A). The offline analysis was conducted using ad hoc MATLAB routines (The MathWorks) to extrapolate single and averaged traces to be analyzed in Clampfit (pClamp10; Molecular Devices). When specified, $200 \mu \mathrm{M}$ L-NAME or a mixture of 100 $\mu \mathrm{M}$ D-APV and $50 \mu \mathrm{M} 7 \mathrm{ClKyn}$ was added to the extracellular solution. In these cases, DAF-FM fluorescence recordings were acquired after $1 \mathrm{~h}$ or $20 \mathrm{~min}$ of drug exposure, respectively. The average distance from the stimulating electrode of the regions where the DAF-FM signal was detected and analyzed was $158 \pm 10 \mu \mathrm{m}(n=20)$, which is in the same range as the distance of the vessels used to analyze microvascular reactivity, as described above (see Fig. 4C).

A caveat about the interpretation of DAF-FM measurements is that this dye does not react directly with $\mathrm{NO}$, but rather with a number of nitrogen derivatives such as $\mathrm{N}_{2} \mathrm{O}_{3}, \mathrm{NO}_{2}$, and ONOO. Nevertheless, a number of observations indicate that the fluorescence signal recorded in our experiments actually reflects the NO released upon MF stimulation. First, the DAF-FM fluorescence signal was fully blocked by L-NAME, which inhibits the NO-synthesizing enzyme NOS and by APV + 7ClKyn, which block NMDA receptors and therefore the calcium influx needed to activate NOS. Second, NO release upon high-frequency MF stimulation was measured directly using electrochemical probes and, similar to the DAF-FM fluorescence signal, was prevented by L-NAME and APV application (Maffei et al., 2003). Finally, because capillary vasodilation depends on NO, its blockage by L-NAME confirms that NO was produced during synaptic stimulation.

\section{Results}

\section{Identification of capillary microvessels in the granular layer of the cerebellum}

Recent studies have shown convincingly that capillaries can respond to neuronal activity by changing their luminal diameter earlier than upstream arterioles, thereby contributing to the initiation of cerebellar BOLD signals (Hall et al., 2014; Attwell et al., 2016). This is due to the presence of contractile pericytes, which ensheath the capillary wall from the outside and make direct contact with endothelial cells (Dalkara and Alarcon-Martinez, 2015; Attwell et al., 2016) controlling microcirculation by sensing the vasoactive messengers released by either neurons or astrocytes located within the neurovascular unit (Peppiatt et al., 2006; Hall et al., 2014). Although this observation has been challenged (Fernández-Klett et al., 2010; Hill et al., 2015), a subsequent reinterpretation supported the critical role of pericytes (Attwell et al., 2016). A recent investigation elegantly described the overall architecture of cerebellar microvessels (Kolinko et al., 2016). Here, we focused our attention on intraparenchymal capillaries (Fig. $1 A$ ), which reside in close contact with GrCs (Fig. $1 A$, asterisks) and are therefore strategically located to sense any changes in local neuronal activity rapidly. Bright-field microscopy revealed that these microvessels have a mean inner diameter of $4.23 \pm 0.29 \mu \mathrm{m}(n=26$; Fig. $1 A)$, which is well within the range expected for brain capillaries (Attwell et al., 2016), and lack a continuous layer of smooth muscle cells. Visual inspection further identified them as capillaries by the characteristic bump-on-a-log location of pericytes on the abluminal wall (Fig. $1 A$, arrows). Accordingly, cerebellar granular layer capillaries were positive to the labeling with isolectin B4 and the proteoglycan NG2 antibody, which bind to the basal membrane and pericytes (Mishra et al., 2014), respectively (Fig. $1 \mathrm{Ba}$ ). Capillaries were not enwrapped by a continuous layer of pericytes (Fig. $1 \mathrm{Ba}$ and colocalization of isolectin B4 and NG2 antibody staining in Fig. $1 B b$ ), which is fully consistent with their original definition by Zimmermann (Zimmermann, 1923; Krueger and Bechmann, 2010; Attwell et al., 2016). Finally, immunostaining with NG2 antibody clearly revealed the conspicuous somata with a bump-on-a-log morphology from which two thinner processes depart that features capillary pericytes (Fig. 1Bc) (Peppiatt et al., 2006; Attwell et al., 2016). Our subsequent analysis of the cellular and molecular underpinnings of NVC in the cerebellar granular layer 
A
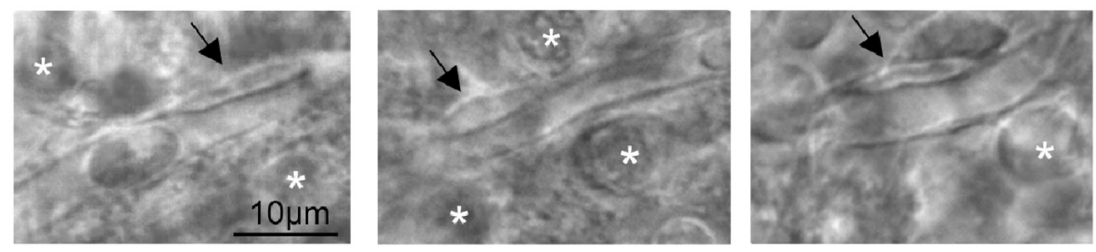

B

a

b

C
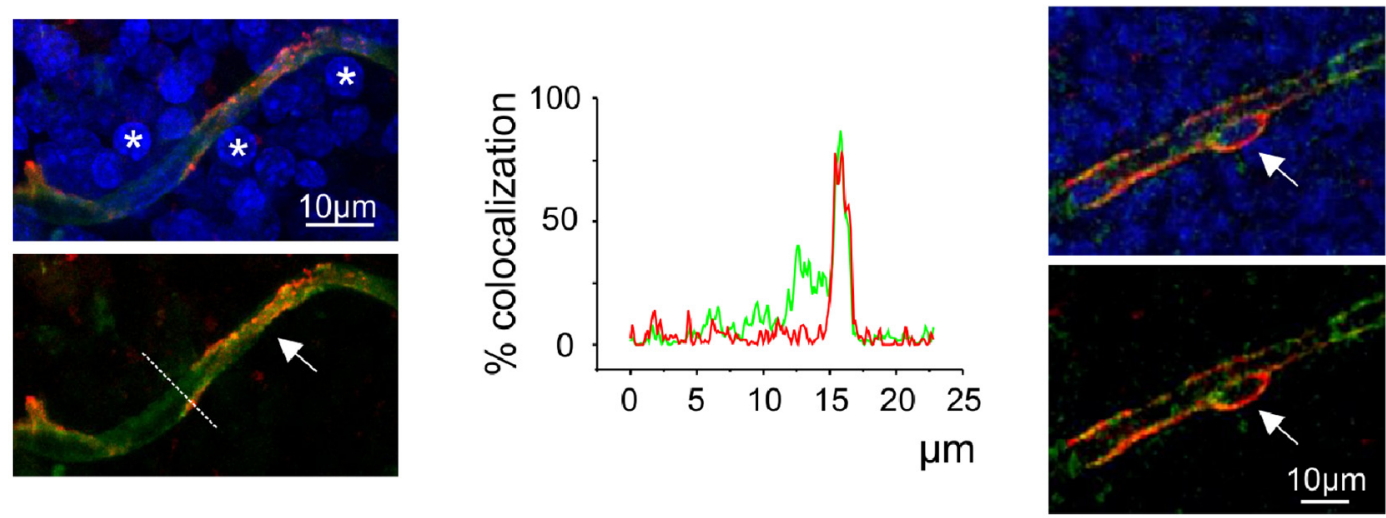

C

a

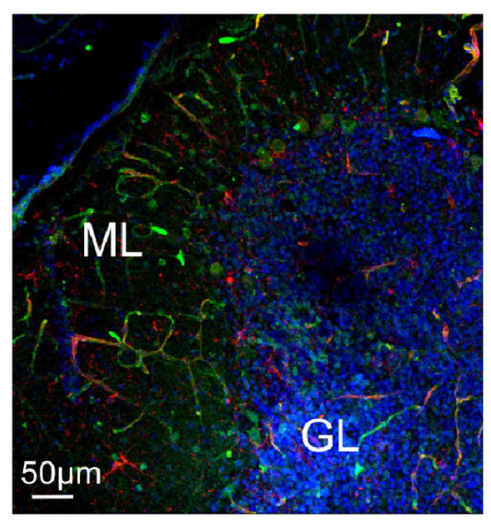

b

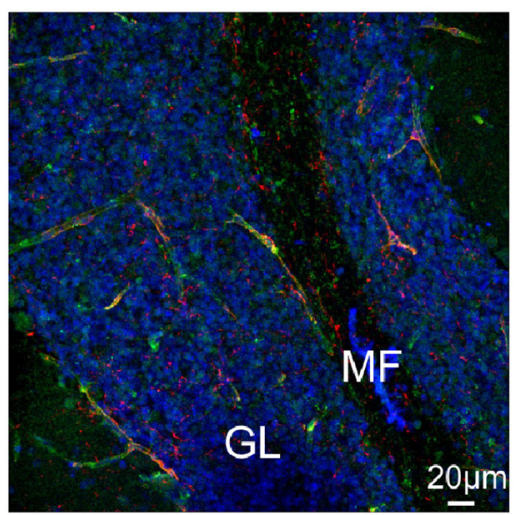

Figure 1. Identification of capillary microvessels in the cerebellar granular layer. $A$, Examples of bright-field images of three capillaries in the cerebellar granular layer. Note that GrCs $(*)$ are in close contact with nearby capillaries. Arrows indicate putative pericytes in close contact with the vessel wall. B, Confocal fluorescent images of cerebellar slices stained for IB4 (green), NG2 (red), and DAPI (blue) to reveal capillaries, pericytes, and cell nuclei, respectively. Ba, Top, Image showing a capillary surrounded by GrCs (*). Bottom, Same capillary (excluding DAPI) reveals the colocalization of IB4 and NG2 staining. The dashed line indicates the section analyzed for IB4-NG2 colocalization in $\boldsymbol{B} \boldsymbol{b}$. B $\boldsymbol{b}$, Colocalization graph showing the overlap of the fluorescence signals originated by capillaries (green) and pericytes (red) staining. $\boldsymbol{B} \boldsymbol{c}$, Granular layer capillary from another staining than in $\boldsymbol{B} \boldsymbol{a}$, where the pericyte soma (arrow) and its bump-on-a-log morphology are visible in close contact with the capillary wall. C, Confocal acquisitions from a cerebellar slice stained for IB4 (green), NG2 (red), and DAPI (blue), as in Ba and BC. Ca, Image showing the more regular microvessel organization in the molecular layer (ML) compared with the granular layer (GL) (20× objective). $(\boldsymbol{b} b$, Image showing the granular layer (GL) and the MF bundle of another lamella at a higher magnification ( $40 \times$ objective).

was therefore performed by evaluating the vascular reactivity of these structures.

We also examined cerebellar slices at a lower magnification $(20 \times$ and $40 \times)$ to gain more insights into the differences in the organization of the vascular network between molecular and granular layers. As depicted in Figure $1 \mathrm{Ca}$, the molecular layer displayed a more regular vascular architecture that consisted of an array of parallel arterioles that originated from the surface of the lamella, penetrated deep into the layer, were interconnected through lateral branches, and gave off capillaries. Figure $1 \mathrm{Cb}$ 
A

a

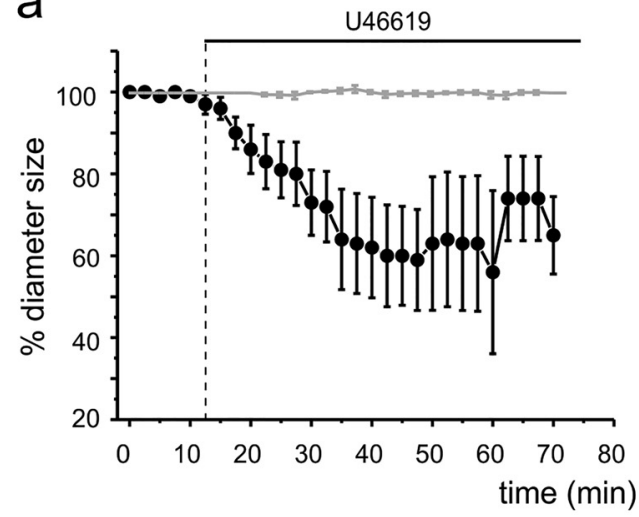

b

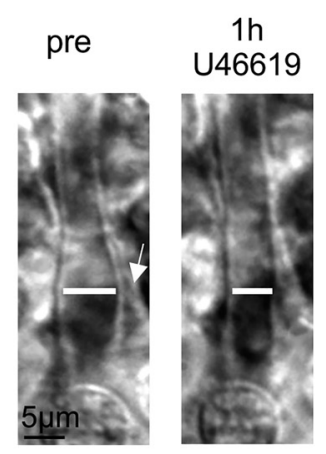

\section{B}

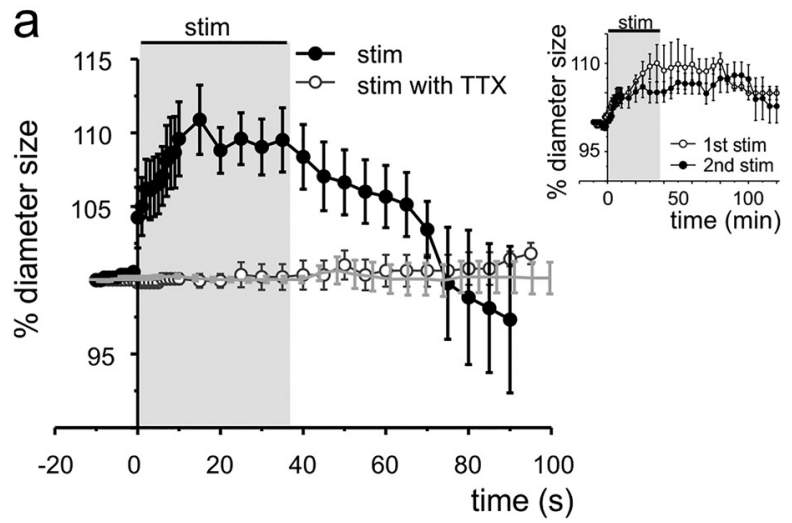

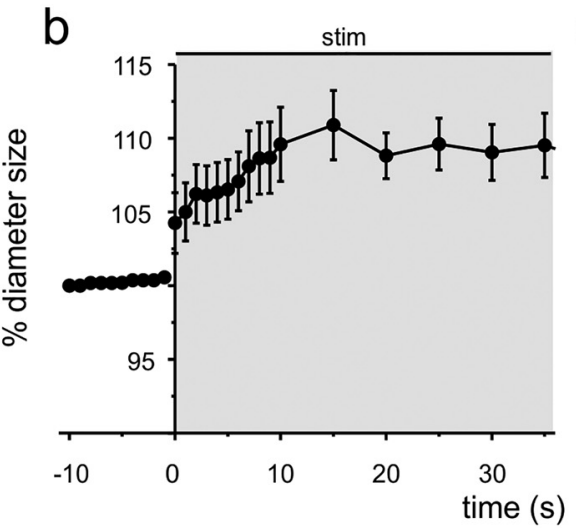

C

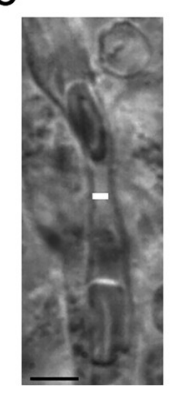

stim

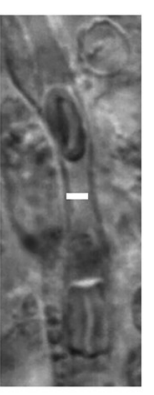

Figure 2. MF stimulation determines capillary vasodilation. $\boldsymbol{A}$, U46619 perfusion restores the vascular tone in the granular layer capillaries. Aa, Average time course of the normalized capillary lumen diameter size in slices incubated for $1 \mathrm{~h}$ with U46619 (a thromboxane A2 agonist; $75 \mathrm{~nm} ; n=7$ ). The gray line shows that capillary diameter did not change in the absence of U46619 perfusion. $\boldsymbol{A} \boldsymbol{b}$, Image showing a capillary before (left) and after U46619 (right) perfusion. White bars indicate the location of lumen diameter measurements near the pericyte indicated by the arrow. $\boldsymbol{B}$, MF stimulation causes vasodilation of preconstricted capillaries. Ba, Average time course of capillary diameter size ( $n=13$ ) before, during (gray filled rectangle) and after (black circles) MF stimulation $(t=0 \mathrm{~s} ; 50 \mathrm{~Hz})$; the gray trace shows the average time course of capillary diameter size in the absence of stimulation $(n=10)$ and the gray empty circles show the average time course of capillary diameter size in the presence of $4 \mu \mathrm{m} \operatorname{TTX}(n=5)$ As a control, in five slices, a second stimulation (after $15 \mathrm{~min}$ ) shows an average vasodilation not statistically different from the first one (inset). $\boldsymbol{B b}$, The same time course in $\boldsymbol{B a}$ is shown on an expanded time scale to appreciate the initial dynamics of vessel dilation during MF stimulation. Note that vasodilation is evident as soon as $1 \mathrm{~s}$ after MF stimulation is started. $B$ c, Images showing capillary diameters before (left) and during (right) MF stimulation. White bars indicate the lumen diameter. In these and all subsequent experiments, capillaries were preconstricted using U46619.

shows that the granular layer is fed by the arterioles incoming from the molecular layer that give raise to a diffused network of capillary vessels enmeshed within the highly compacted GrCs.

\section{MF stimulation causes vasodilation in the microcirculation of the cerebellar granular layer}

To investigate the vasomotor response to MF stimulation, cerebellar brain slices were preincubated with the thromboxane A2 agonist U446619 (75 nM), as described previously (Rancillac et al., 2006). This is an established approach to reproduce the vascular tone in unperfused and unpressurized brain microvessels (Fernández-Klett et al., 2010; Mishra et al., 2014). We did not preconstrict the capillaries with noradrenaline, as suggested previously (Hall et al., 2014), because earlier work showed that this neurotransmitter may also activate rat cerebellar GrCs (Xu and Chuang, 1987; Dillon-Carter and Chuang, 1989). As depicted in Figure 2, $A a$ and $A b$, U46619 caused a slowly developing vasoconstriction in the granular layer because the capillary diameter decreased to $\sim 60 \%$ of its initial value 45 min after drug perfusion $(-39.9 \pm 12.1 \% ; n=7 ; p=0.02)$. The vasomotor response to
U46619 was usually spatially restricted at pericyte locations (Fig. 2Ab, arrow), which therefore serve as sphincter-like structures that control microvascular blood flow, as has also been reported in the molecular layer (Rancillac et al., 2006; Hall et al., 2014). Control experiments confirmed that capillary diameter did not undergo any significant change in the absence of U46619 (Fig. 2Aa, gray trace). Under these conditions, high-frequency MF stimulation caused a significant capillary vasodilation at spatially restricted locations near pericytes (Fig. 2Bc). The kinetics and magnitude of the hemodynamic signal evoked by neuronal activity are shown in Figure $2 \mathrm{Ba}$. The changes in vascular tone started immediately after the stimulus and consisted in a rapid initial vasodilation, followed by a slower increase in lumen diameter $(10.9 \pm 2.4 \%, n=13 ; \mathrm{p}=0.00006)$ that peaked within $20 \mathrm{~s}$ $(16.5 \pm 2.6 \mathrm{~s} ; n=13)$ from the onset of the response and returned to the baseline within $20 \mathrm{~s}(16.4 \pm 8.6 \mathrm{~s} ; n=13)$ after interruption of the train. Figure $2 \mathrm{Bb}$ displays an enlargement of the early phase of activity-induced vasodilation: it clearly shows that capillary diameter increased by $5 \pm 2 \%(n=13)$ already at $1 \mathrm{~s}$ after MF stimulation. This issue is particularly relevant when considering 
that Poiseuille's law predicts that blood flow is directly proportional to the fourth power of the vessel radius; therefore, the activation of the MF-GrC synapse could boost local blood flow rapidly and by as much as $13 \%$ (see Discussion). To confirm the synaptic dependence of this process, cerebellar slices were preincubated in the presence of tetrodotoxin (TTX; $4 \mu \mathrm{M}$ ), a selective inhibitor of voltage-dependent $\mathrm{Na}^{+}$channels. As shown in Figure $2 B a$, MF stimulation failed to cause any evident change in capillary diameter under these conditions, thereby providing evidence that synaptic activity also controls the microvascular tone in the granular layer $(0.19 \pm 0.87 \%, n=5 ; p=0.8)$.

\section{NMDARs and NO mediate vasodilation upon MF stimulation} We have shown previously that high-frequency MF stimulation causes a robust NMDAR- and NOS-dependent NO release in the granular layer of rat cerebellar slices (Maffei et al., 2003). Therefore, we first assessed whether NMDAR blockage affects the vasomotor response to synaptic activity. The coapplication of D-APV $(100 \mu \mathrm{M})$ and 7ClKyn $(50 \mu \mathrm{M})$, which specifically target NMDARs, transformed the vasodilation evoked by MF stimulation into a significant vasoconstriction (Fig. $3 A$ ). The decrease in capillary diameter started immediately (i.e., $1 \mathrm{~s}$ ) after the delivery of the stimulus, achieved a steady-state level $(-5.9 \pm 1.8 \%, n=7$; $p=0.02)$ within $20 \mathrm{~s}(19.5 \pm 3.9 \mathrm{~s} ; n=7)$, and returned to the baseline within $\sim 21 \mathrm{~s}(21.3 \pm 27.7 \mathrm{~s} ; n=7)$ after interruption of the high-frequency train. Therefore, the kinetics of the vasoconstricting response to synaptic activity mirrors the vasodilation occurring when NMDARs are functional. Control experiments confirmed that two consecutive stimuli delivered at 15 min intervals from each other elicited the same hemodynamic signal in the absence of any pharmacological treatment (first: $10.0 \pm 3.1 \%$, $n=5 ; p=0.01$; second: $6.0 \pm 1.8 \%, n=5 ; p=0.0004$; first vs second dilation not statistically different, $p=0.2$; Fig. $2 B$, inset).

The role played by $\mathrm{NO}$ in NVC at the MF-GrC relay was investigated by using the selective NOS inhibitor L-NAME, that is widely used to prevent NO release (Mehta et al., 2008). Our preliminary experiments revealed that the addition of L-NAME $(200 \mu \mathrm{M})$ to U46619-preconstricted cerebellar slices caused a further $40 \%$ reduction in microvessel diameter $(-55.7 \pm 2.8 \%$; $n=8 ; \mathrm{p}=0.004$; Fig. $3 B$, inset), which is consistent with the tonic NO release by vascular endothelial cells (Hopper and Garthwaite, 2006). Control experiments showed that capillary diameter did not undergo any significant change in the absence of L-NAME perfusion (Fig. 3B, inset, gray trace). As observed upon inhibition of NMDARs, stimulation-evoked vasodilation reversed to vasoconstriction in the presence of L-NAME (Fig. 3B). The vasoconstrictor response initiated at $1 \mathrm{~s}$, reached a plateau $(-9.0 \pm 1.4 \%$, $n=9$ of $9 ; p=0.000004)$ at $35 \pm 3 s(n=9)$, and did not fully return to resting levels upon interruption of the stimulus. Similar results were obtained when the slices were preincubated with ODQ (10 $\mu \mathrm{M}$; mean, $-3.6 \pm 0.9 \% ; n=10 ; p=0.005$; Fig. $3 C)$, an inhibitor of soluble NO-dependent guanylyl cyclase (sGC) activity (Sakagami et al., 2001). As expected by the block of sGC activation by NO, ODQ prevented pericyte-dependent vasodilation, whereas it did not affect pericyte-dependent vasoconstriction in the presence of L-NAME $(-8.2 \pm 1.7 \%, n=8 ; p=0.001$; vs L-NAME alone $-12.8 \pm 1.9 \%, n=8 ; p=0.00005$; the two vasoconstrictions are not statistically different, $p=0.1$; Fig. $3 \mathrm{Ba}$ ).

Together, these data demonstrate that activation of the MF-GrC relay decreases the microvascular tone and increases local CBF by recruiting NMDARs and NOS. GrCs express both NMDARs and nNOS (Southam et al., 1992; D'Angelo et al., 1995; Maffei et al., 2003), whereas cerebellar glial cells and brain endo- thelial cells lack functional NMDARs (Busija et al., 2007; Dzamba et al., 2013). Therefore, GrCs are the most likely candidates to trigger the vasoactive response to MF stimulation. To further support these conclusions, we exploited a high-resolution imaging system to measure NO production directly in the granular layer of cerebellar slices loaded with the NO-sensitive dye DAF-FM, as reported below.

\section{Evidence for NO production in the granular layer}

Previous results showed NO production by GrCs in the granular layer indirectly in response to MF stimulation. To obtain evidence of NO production in the granular layer, we loaded the slices with the DAF-FM dye. DAF-FM fluorescence is related to NO production (as well as NO production derivates) inside cells with fast reaction kinetics (Balcerczyk et al., 2005; Namin et al., 2013). Therefore, the DAF-FM signal is thought to reflect intracellular NOS activity, rather than extracellular NO accumulation. To investigate neuronal-activity-dependent $\mathrm{NO}$ production in the granular layer after MF stimulation, we detected DAF-FM fluorescence changes during a $5 \mathrm{~s}$ trial, with $4 \mathrm{~s} 50 \mathrm{~Hz}$ MF stimulation. To enhance the signal-to-noise ratio, pure noise was averaged out by subtracting the average of four trials without MF stimulation to that of four trials with MF stimulation four, allowing the subtraction of the stimulus-independent component of the fluorescence signal (acquisition rate was set at $15 \mathrm{~ms}$; see Materials and Methods for a detailed description of the procedure). Interestingly, the granular layer responded to MF stimulation with a fluorescence signal peak at $212.8 \pm 20.5 \mathrm{~ms}$ delay and an average fluorescence at peak of $0.029 \pm 0.003 \Delta F / F_{0}(n=20$; Fig. $4 A)$. The analysis of the average trace in Figure $4 A$ resulted in a rise time $(10-90 \%)$ of $25.6 \mathrm{~ms}$, a decay time $(90-10 \%)$ of $95.5 \mathrm{~ms}$, and a half-width of $55.0 \mathrm{~ms}$. Notably, these values are in good agreement with the nNOS kinetics described previously (Salerno, 2008; Salerno and Ghosh, 2009; Garthwaite, 2016), supporting the role of nNOS as a primer of activity more than a "classic" enzyme with a Michaelis-Menten steady-state kinetics (Salerno, 2008).

Because the DAF-FM signal could be influenced by other NOrelated chemical species, we repeated the same recordings after NOS blockage using $200 \mu \mathrm{M}$ L-NAME perfusion for at least $1 \mathrm{~h}$. In the presence of L-NAME, the fluorescence peak was no longer observed $\left(0.001 \pm 0.003 \Delta F / F_{0}{ }^{*} \mathrm{~ms}\right.$ at the time of peak in control, $n=7$; Fig. $4 B$ ). Moreover, we tested the neuronal origin of the signal by blocking NMDARs using $100 \mu \mathrm{M}$ D-APV and $50 \mu \mathrm{M}$ 7ClKyn and repeated the same experiment after at least $20 \mathrm{~min}$ of blocker perfusion. Again, the fluorescence peak triggered by MF stimulation was no longer observed $\left(-0.007 \pm 0.006 \Delta F / F_{0}{ }^{*} \mathrm{~ms}\right.$ at the time of peak in control, $n=6$; Fig. $4 B$ ). Moreover, the distance from the stimulating electrode of the fluorescence signals ( $158 \pm 10 \mu \mathrm{m}, n=20$ ) was comparable to the distance of the vessels used for the analysis (191 $\pm 10 \mu \mathrm{m}, n=50$, N.S.), as evident in the scatter plot in Figure $4 C$. Therefore, we provide evidence that the MF stimulation used could indeed determine neuronal NO production at the distances used for the analysis of stimulus-induced vessel diameter changes.

\section{mGluRs and 20-HETE mediate vasoconstriction in the absence of NO release}

The question then arose as to the molecular nature of the vasoactive agent inducing vasoconstriction in the absence of $\mathrm{GrC}$-derived $\mathrm{NO}$. NO may inhibit the enzyme CYP $\omega$-hydroxylase, thereby suppressing the synthesis of 20-hydroxyeicosatetraenoic acid (20-HETE) (Attwell et al., 2010), which has been shown recently to increase the 
A

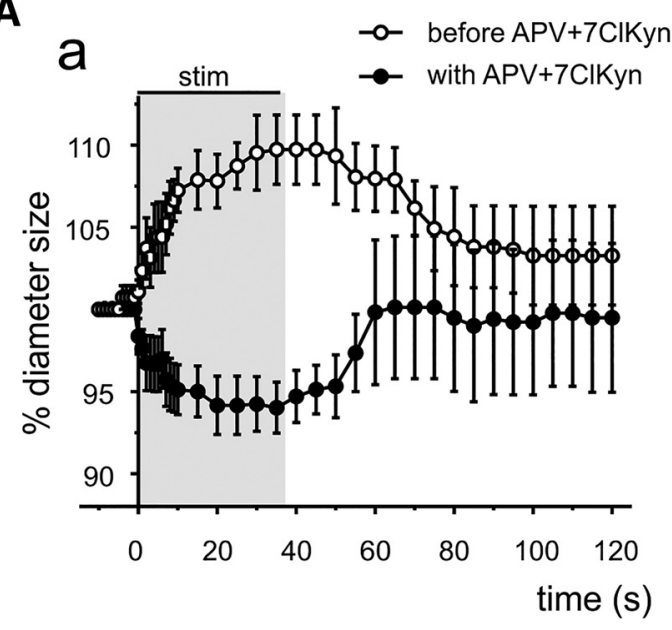

b

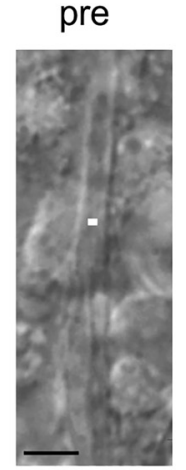

stim

stim APV+7ClKyn
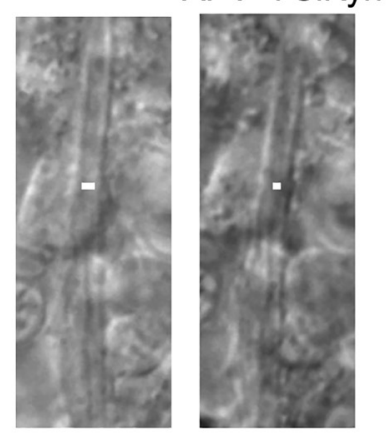

B

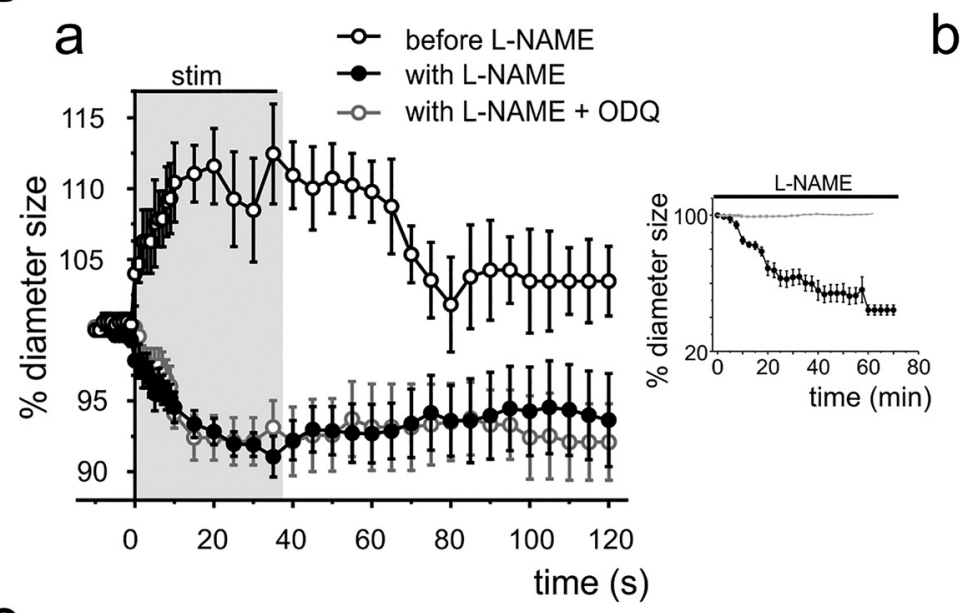

b pre L-NAME stim L-NAME
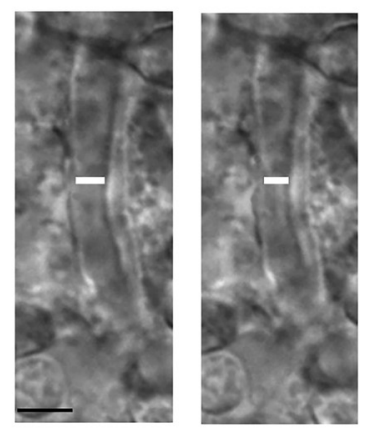

C

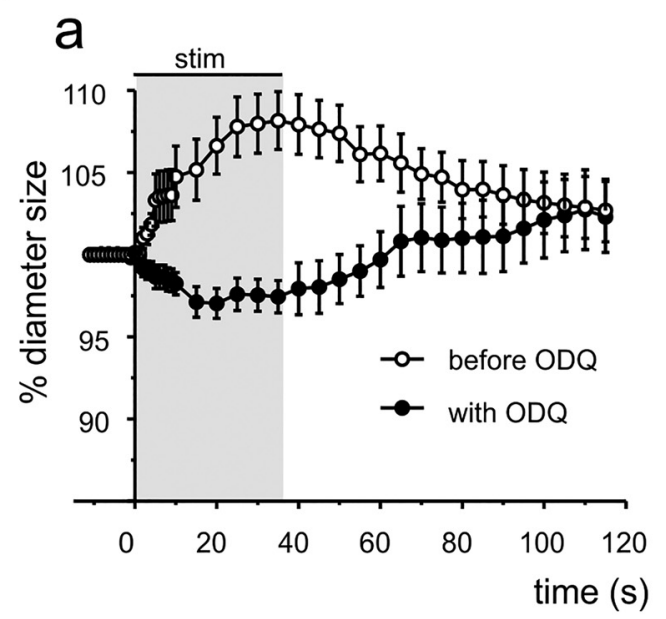

b

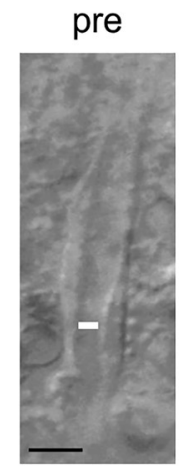

stim

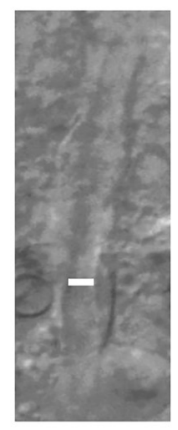

stim ODQ

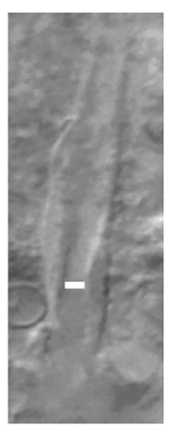

Figure 3. NMDARs, NO, and CGMP mediate vasodilation. $\boldsymbol{A}$, Capillary vasodilation depends on NMDAR activation. Aa, Average time course of capillary diameter changes during the same MF stimulation protocol shown in Figure $2 B$ in control (open circles) and during (filled circles) APV + 7CIKyn perfusion (NMDAR inhibitors; 100 and $50 \mu$, respectively; $n=7$; the vessels diameter at the end of the control stimulation is renormalized to show the relative size changes after the stimulation in APV +7 (IKyn). NMDARs blockage turns the vasodilation into a vasoconstriction. $A \boldsymbol{b}$, Images showing capillary diameters before (left), during MF stimulation in control (center), and during MF stimulation in the presence of APV + 7CIKyn (right). White bars marks lumen diameter. $\boldsymbol{B}$, NO production is necessary for vasodilation. Ba, Average time course of the capillary diameter changes during theMF stimulation protocol before (blackempty circles) and after (filled circles) L-NAMEperfusion (a NOS inhibitor; $200 \mu \mathrm{M}, n=9$ ) and after L-NAME and $10 \mu \mathrm{MODQ}$ perfusion (gray empty circles). The stimulus-evoked vasodilation is turned into vasoconstriction in both cases. Note that, during the hour ofL-NAME perfusion, the vessel diameter decreases (black circles, $n=8$; compared with controls without L-NAME perfusion, gray line, $n=5$ ) as shown in the inset. The vessel diameter relative size reported in the graph is therefore renormalized to the prestimulus condition in L-NAME. Bb, Images showing capillary diameter before (left) and after (right) MF stimulation in slices treated with L-NAME ( $1 \mathrm{~h})$. White bars indicate the lumen diameter. $\mathbf{C}, \mathrm{sGC}$ activation by N0 is involved in vasodilation. Ca, Average time course of capillaries diameter size during the stimulation protocol before (empty circles) and after (filled circles) $0 \mathrm{DQ}$ perfusion (an $\mathrm{sGC}$ inhibitor; $10 \mu \mathrm{m} ; n=10$ ). The blockage of $\mathrm{SGC}$ activity abolishes vasodilation that is partially reversed toward vasoconstriction. $\boldsymbol{C b}$, Images showing the same capillary before (left) and during MF stimulation in control (center) and in the presence of $\mathrm{ODQ}$ (right). White bars indicate the lumen diameter. 
A

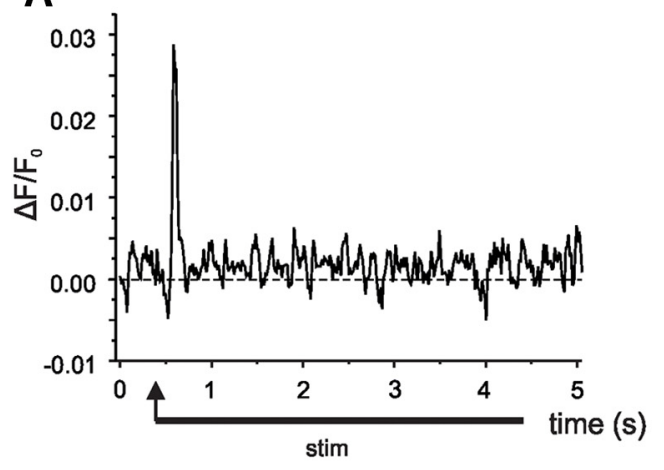

B
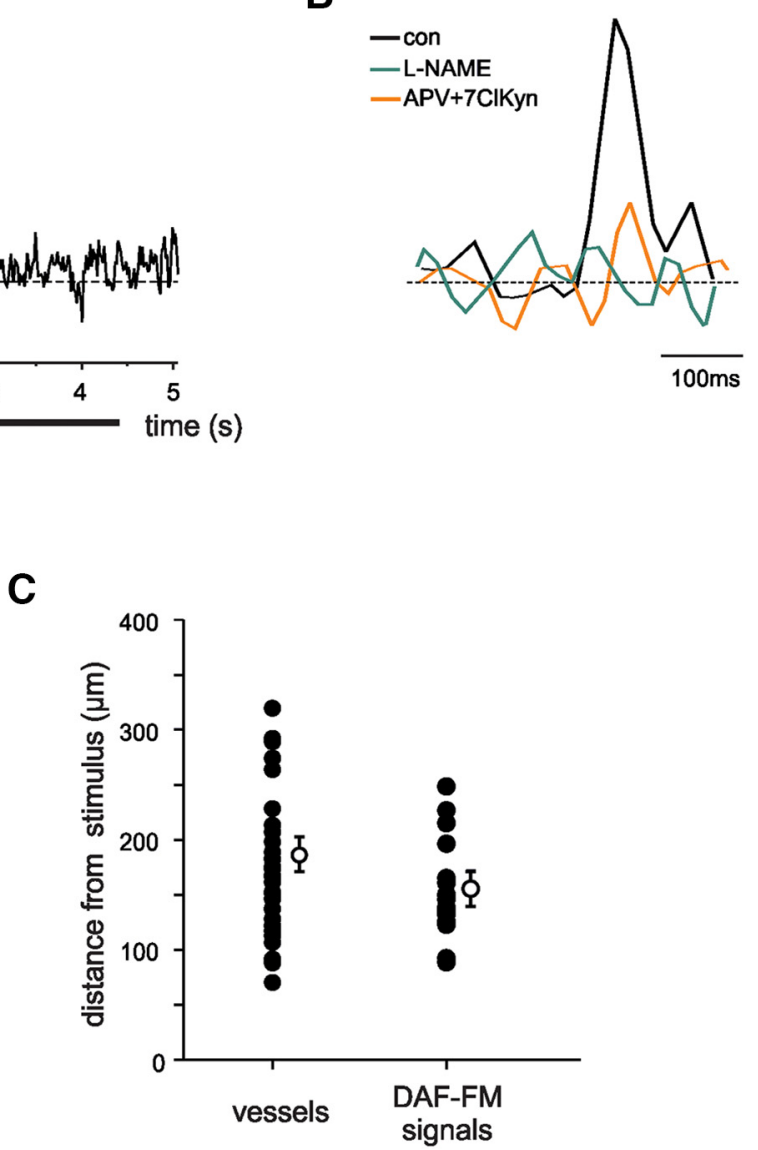

Figure 4. DAF-FM fluorescence induced by synaptic activity in the granular layer. A, Average trace showing the peak in DAF-FM fluorescence in response to $4 \mathrm{~s}$ MF stimulation ( $n=20$ slices). $\boldsymbol{B}$, Average traces of DAF-FM fluorescence signals evoked as in $\boldsymbol{A}$ in cerebellar granular layers before (black) and after $1 \mathrm{~h}$ of L-NAME perfusion (green; $200 \mu \mathrm{m} ; n=7$ ) and after APV +7 CIKyn perfusion (orange; 100 and $50 \mu \mathrm{m}$, respectively; $n=6$ ). The superimposed traces are on the same amplitude scale as in $A$, whereas the time scale is dilated to appreciate the fluorescence peaks. C, Scatter plot showing the distances from the stimulating electrode of each vessel and DAF-FM fluorescence signal analyzed (filled circles). The empty circles show the average values of the single points.

contractile tone in cerebellar pericytes (Hall et al., 2014). Therefore, 20-HETE is a suitable candidate to mediate the reduction in the microvascular tone of the granular layer unveiled by NOS inhibition. To address this issue, cerebellar slices were pretreated with L-NAME $(200 \mu \mathrm{M}, 1 \mathrm{~h})$ to prevent NO production and then perfused with HET-0016 $(1 \mu \mathrm{M})$ to block 20-HETE synthesis by CYP $\omega$-hydroxylase (Metea and Newman, 2006). Control experiments revealed that this treatment did not alter the hemodynamic signal recorded in the absence of L-NAME $(4.1 \pm 1.2 \%, n=4 ; p=0.04$; vs $6.3 \pm 2.2 \%, n=$ $4 ; p=0.0005$; respectively; not statistically different dilations, $p=$ 0.4; Fig. 5A). However, as displayed in Fig. 5B, HET-0016 reduced neuronal activity-dependent vasoconstriction significantly (mean $-4.2 \pm 1.9 \% ; n=9 ; p=0.007$ ) in the presence of L-NAME. Moreover, HET-0016 $(1 \mu \mathrm{M})$ reduced the vasoconstriction response to MF stimulation significantly upon NMDAR inhibition with D-APV $(100 \mu \mathrm{M})$ and $7 \mathrm{ClKyn}(50 \mu \mathrm{M})(-2.1 \pm 0.7 \%, n=5 ; p=0.02$; vs $-5.2 \pm 2.5 \%, n=5 ; p=0.005$; statistically different constrictions, $p=0.02$; Fig. $5 C$ ). These findings lend support to the hypothesis that 20-HETE plays a key role in NVC in the granular layer of the cerebellum when NO release is hampered. According to the most popular model (Attwell et al., 2010; Duchemin et al., 2012), 20-HETE is synthesized from arachidonic acid (AA) liberated by astrocytes upon synaptic stimulation. Accordingly, synaptically released glutamate could activate mGluRs expressed on the perisynaptic end feet of nearby astrocytes, thereby leading to $\mathrm{Ca}^{2+}$-dependent activation of phospholipase A2 (Mulligan and MacVicar, 2004; Attwell et al., 2010). If this were also true in the granular layer of the cerebellum, then inhibiting mGluRs should attenuate neuronal activity-evoked vasoconstriction occurring in the presence of L-NAME. Consistent with this hypothesis, the broad-spectrum mGluR antagonists MCPG (500 $\mu \mathrm{M})$ and CPPG (300 $\mu \mathrm{M})$ abolished the vasoconstrictor response to MF stimulation in L-NAME-pretreated slices (mean $1.1 \pm 1.5 \% ; n=15 ; p=0.9$ Fig. $5 D$ ). These data support the conclusion that mGluRs drive the synthesis of 20-HETE during synaptic transmission at the MF$\mathrm{GrC}$ relay. The interaction between these two diverging vasoactive pathways, $\mathrm{NO}$ and 20-HETE, could have profound implications for the mechanism of NVC at the input stage of the cerebellum.

\section{Discussion}

In this study, we demonstrate that synaptic activation of the cerebellar granular layer causes capillary vasodilation through an NMDAR/NOS-dependent mechanism. It is probable that the main neurons involved are GrCs, which represent the largest neuronal population and express NMDARs and nNOS at the highest levels in the brain (Monaghan and Anderson, 1991; Snyder, 1992; Southam et al., 1992). GrCs actually produce NO under NMDAR activation, causing smooth muscle relaxation in in vitro systems (Garthwaite and Garthwaite, 1987; Garthwaite et al., 1989). The present result thus focuses the NVC mechanism onto these small neurons forming the NOergic backbone of the cerebellum and releasing $\mathrm{NO}$ also in the molecular layer through parallel fibers (D'Angelo, 2014), whereas the most renowned Purkinje cells do not express nNOS or produce NO (Rancillac et al., 2006). Interestingly, GrCs display strong burst-related activity fluctuations in vivo (Chadderton et al., 2004; Rancz et al., 2007; Powell et al., 2015) and are therefore especially suited to coordinate NVC, wheres Purkinje cells usually show frequency-modulated activity changes (Bosman et al., 2010; Herzfeld et al., 2015; Cheron et al., 2016; Ramakrishnan et al., 2016). The Golgi cells, which also express NMDARs and nNOS (Southam et al., 1992; Christie and Jahr, 2008; Robberechts et al., 2010), could contribute to the response. The present results also suggest the involvement of cellular elements other than neurons, including pericytes and glial cells, in the local control of microcirculation. Therefore, the granular layer emerges as an integrated cellular system capable of controlling NVC in the cerebellar circuit.

\section{Neuronal activity controls NVC in the cerebellar granular layer}

Capillaries in the cerebellar molecular layer may dilate in response to sensory stimulation earlier than upstream arterioles 
A

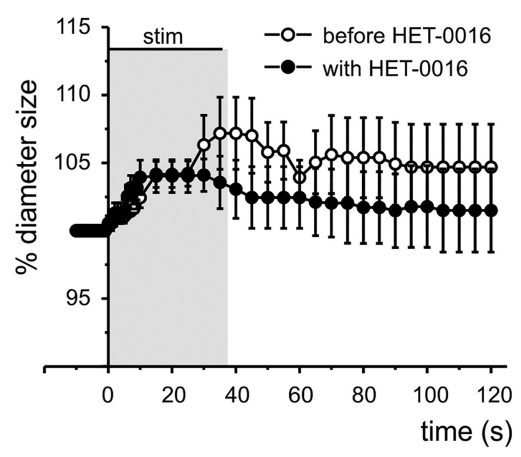

B a

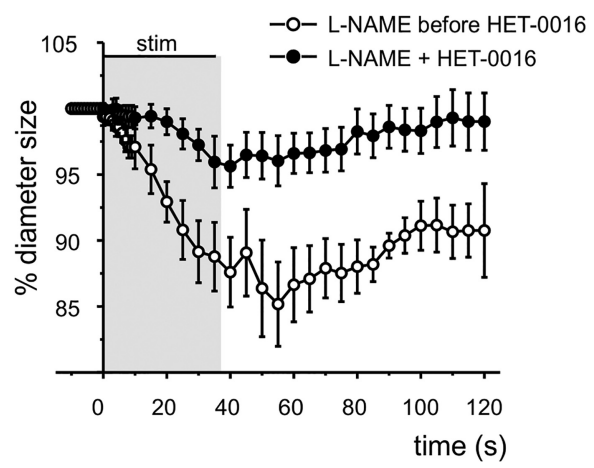

C a

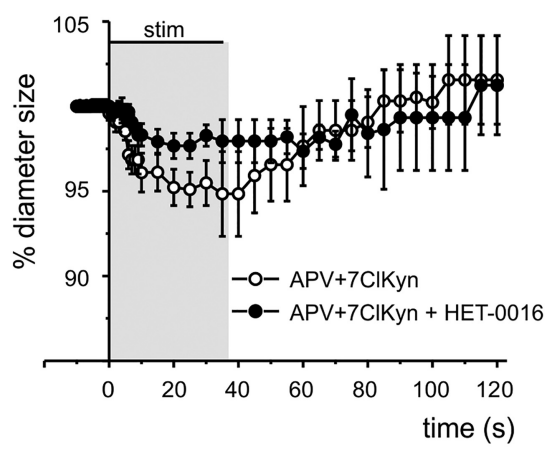

D a

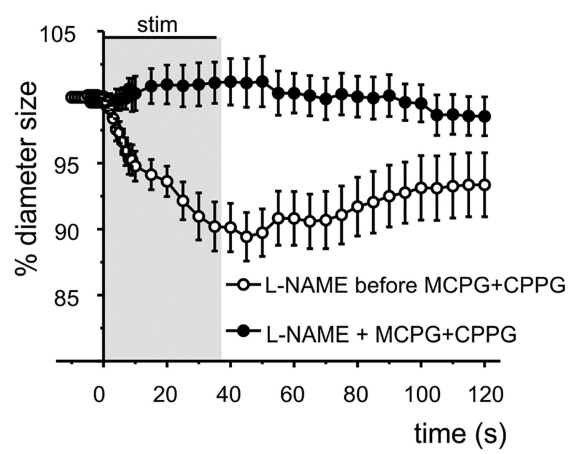

b

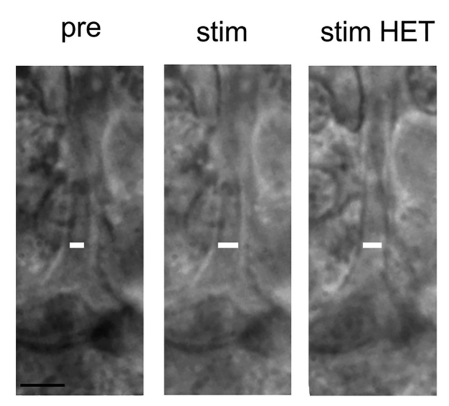

b

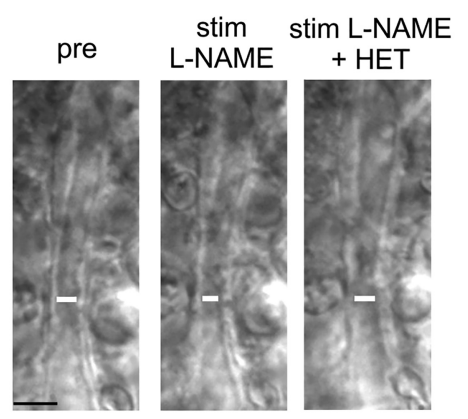

b

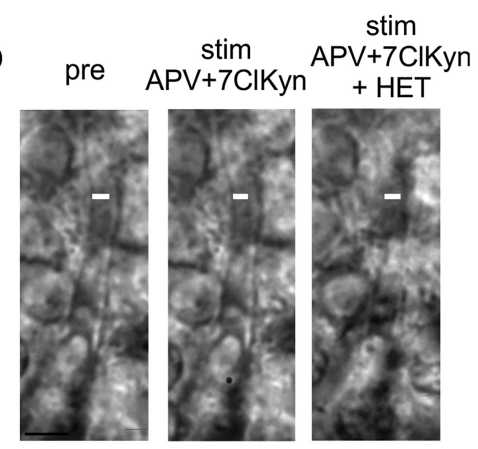

b

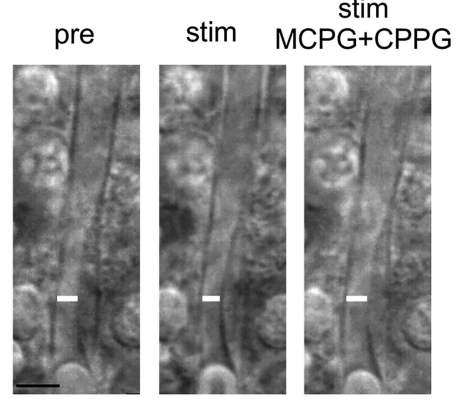

Figure 5. 20-HETE and mGluRs mediate vasoconstriction. $\boldsymbol{A}, 20$-HETE does not influence vasodilation. Aa, Average time course of capillary diameter size in cerebellar slices during the same MF stimulation protocol as in Figures $2 B$ and 3 before (empty circles) and after $1 \mathrm{~h}$ of HET-0016 perfusion (a CYP $\omega$-hydroxylase inhibitor; $1 \mu \mathrm{m} ; n=4$ ). The presence of HET-0016 does not change vasodilation significantly. $\boldsymbol{A} \boldsymbol{b}$, Images showing the diameter variation of a capillary before (left) and during MF stimulation in the absence (center) or presence (right) of HET-0016. White bars indicate the lumen diameter. $\boldsymbol{B}, \boldsymbol{C}, 20$-HETE is the main

and contribute substantially to increase CBF in vivo (Hall et al., 2014). Consistently, in the granular layer, the application of a high-frequency train to MFs caused a robust capillary vasodilation that occurred at pericyte locations. This feature supports the role played by these contractile cells in the regional control of CBF (Attwell et al., 2016).

After MF stimulation, vasorelaxation showed biphasic kinetics. According to Poiseuille's law, the initial ( $\sim 5 \%)$ and late $(\sim 10 \%)$ diameter changes are predicted to reduce capillary resistance by $17 \%$ and $32 \%$, respectively (Peppiatt et al., 2006; Hall et al., 2014). Therefore, with a 45:100 capillary:artery(arteriole) ratio (venule resistance is considered negligible), the total flow resistance would decrease by 5.5\% and 10.3\% (Peppiatt et al., 2006; Hall et al., 2014) and the blood flow would increase by $5.8 \%$ and $11.5 \%$, respectively (see Materials and Methods for calculations).

Because capillaries are significantly closer to neurons than upstream arterioles (8-23 $\mu \mathrm{m}$ vs $70-160 \mu \mathrm{m}$ according to Attwell et al., 2010), the robust increase in local CBF evoked by MFs activation would seemingly satisfy the high metabolic demand of granular layer neurons, which consume as much as $67 \%$ of cerebellar energy (Howarth et al., 2010).

Moreover, the BOLD effect is contributed both by an increase in CBF (which

$$
\leftarrow
$$

vasoconstriction agent. $\boldsymbol{B a}$, Average time course of capillary diameter size in slices exposed to $1 \mathrm{~h} \mathrm{~L}$-NAME during the same MF stimulation protocol as in $A$ before (empty circles) and during (filled circles) HET-0016 perfusion (a CYP $\omega$-hydroxylase inhibitor; $1 \mu \mathrm{m} ; n=9$ ). Note that the blockage of 20-HETE synthesis reduced vasoconstriction. $\boldsymbol{B} \boldsymbol{b}$, Images showing the diameter variations of the same capillary after $1 \mathrm{~h}$ of L-NAME perfusion before (left) and during MF stimulation in the absence of (center) and in the presence of (right) HET-0016. White bars indicate the lumen diameter. $\mathbf{C a}$, Average time course of capillary diameter size in slices perfused with APV + 7CIKyn (as in Fig. 3A) during MF stimulation before (empty circles) and during (filled circles) HET-0016 perfusion. $(\boldsymbol{b}, \mathrm{Im}$ ages showing the changes in capillary diameter after perfusion with APV + 7CIKyn before (left) and during MF stimulation in the absence (center) or presence (right) of HET-0016. White bars indicate the lumen diameter. $\boldsymbol{D}$, Capillary vasoconstriction depends on mGluR activation. Da, Average time course of capillary responses in cerebellar slices exposed to $1 \mathrm{~h}$ of L-NAME after the MF stimulation protocol in the absence (empty circles) or presence (filled circles) of MCPG + CPPG (mGluR blockers; 500 and $300 \mu \mathrm{m}$, respectively; $n=15$ ). The perfusion of mGluR antagonists abolishes stimulus-evoked vasoconstriction. $\boldsymbol{D b}$, Images showing the changes in capillary diameter before (left) and during MF stimulation in the absence (center) or presence (right) of MCPG + CPPG. White bars indicate the lumen diameter. 
tends to increase the signal by washing out deoxyhemoglobin) and by the cerebral metabolic rate of $\mathrm{O}_{2}\left(\mathrm{CMRO}_{2}\right.$, which tends to decrease the signal by generating more deoxyhemoglobin). Therefore, the rapid ( $1 \mathrm{~s}$ ) step-like increase in capillary diameter (Fig. $2 \mathrm{~B}$ ) will boost the $\mathrm{CBF} / \mathrm{CMRO}_{2}$ ratio and the $\mathrm{BOLD}$ signal more efficiently than a gradual relaxation. As further illustrated below, this hemodynamic response reflects $\mathrm{GrC}$ activity faithfully. Intriguingly, recent $7 \mathrm{~T}$ fMRI studies showed that the BOLD signal onset in the gray matter is associated with the capillary bed (Siero et al., 2011; Siero et al., 2013). In this view, the control of microvascular tone at capillary level is the most efficient means with which to redistribute CBF to the highly restricted ( $<3 \mathrm{~mm}$ diameter) activation patches that 7 $\mathrm{T}$ fMRI analysis revealed in the cerebellum in response to single finger stimulation or movement (Wiestler et al., 2011).

\section{Granular layer neuronal activity determines NMDAR/NO-dependent vasodilation}

Four lines of evidence indicate that synaptically released glutamate recruits NMDARs located on postsynaptic granular layer neurons to trigger NO-dependent vasodilation.

First, the hemodynamic signal was turned into vasoconstriction by the pharmacological inhibition of either NMDARs or NOS. NMDARs determine the extent of $\mathrm{GrC}$ activation by MFs (D’Angelo et al., 1995; D'Angelo et al., 1999). Conversely, rat cerebellar Bergman glial cells and brain endothelial cells lack functional NMDARs (Usowicz et al., 1989; Domoki et al., 2002; Dzamba et al., 2013).

Second, imaging of DAF-FM fluorescence supported the notion that NMDARs control NO production in granular layer neurons upon MF stimulation. Although DAF-FM measurements do not reveal NO directly, but rather other cross-reactive species (Balcerczyk et al., 2005), the increase in fluorescence immediately followed MF stimulation, was inhibited by either L-NAME or $\mathrm{APV}+7 \mathrm{ClKyn}$, and strongly resembled the kinetics of neuronal NO production revealed with different techniques (Salerno, 2008; Salerno and Ghosh, 2009; Garthwaite, 2016).

Third, NO activates sGC to elevate $[\mathrm{cGMP}]_{\mathrm{i}}$ and induces vasodilation in the cerebellum (Yang and Iadecola, 1997, 1998). Accordingly, ODQ mimicked the effects of L-NAME by turning vasodilation into vasoconstriction. Given the kinetics of sGC activation and its exquisite sensitivity to NO (Griffiths et al., 2003; Batchelor et al., 2010; Garthwaite, 2016), cGMP production can outlast the NO pulse, which is likely to account for the slower kinetics of the ensuing vasorelaxation.

Fourth, NADPH-diaphorase staining revealed that nNOS, the NOS isoform that converts NMDAR-mediated $\mathrm{Ca}^{2+}$ inflow into NO release (Garthwaite, 2016), is expressed abundantly in GrCs, but not in cerebellar astrocytes or endothelial cells (Southam et al., 1992).

The combination of the present DAF-FM measurements with NADPH-diaphorase staining (Southam et al., 1992), NOS immunohistochemistry (Snyder, 1992), and electrochemical NO determination (Maffei et al., 2003) provides solid evidence that NO was generated by granular layer neurons. The GrCs, which outnumber Golgi cells by $\sim 2000$ times in rats (Korbo et al., 1993) and show prominent NMDAR-dependent responses (D'Angelo et al., 1995), are likely to play the major role, although the contribution of Golgi cells (which also express NMDARs and nNOS) (Southam et al., 1992; Cesana et al., 2013; D’Angelo et al., 2013) cannot be ruled out.

\section{Non-neuronal antagonistic systems balance the capillary diameter}

In addition to promoting vasodilation, $\mathrm{NO}$ released by granular layer neurons could inhibit the synthesis of the potent vasoconstrictor 20-HETE (Attwell et al., 2010). Accordingly, when NO production was suppressed by blocking NMDARs or NOS, MF stimulation resulted in a marked vasoconstriction that was antagonized by HET-0016. 20-HETE could be generated by pericytes metabolizing AA released upon activation of mGluRs located on perisynaptic astrocytes (Attwell et al., 2010; Sweeney et al., 2016). In support of this model, a mixture of selective mGluR inhibitors abolished synaptic-activity-dependent vasoconstriction. Combined application of inhibitors of NOS, NMDAR, sGC, and CYP showed that NO does not need to prevent 20-HETE formation to induce capillary vasorelaxation in the granular layer because it acts via cGMP (Hall et al., 2014). This is in contrast to the molecular layer, in which vasodilation is triggered by prostaglandin E2, but NO plays a permissive role by suppressing 20-HETE synthesis (Hall et al., 2014). This model would also explain why the vasoconstriction observed in the presence of ODQ was smaller than with L-NAME, with NO being still released and partially inhibiting the vasoconstriction branch depending on 20-HETE synthesis. The difference between molecular and granular layer mechanisms may (at least in part) be related to the different architecture of their microvascular networks (Kolinko et al., 2016). Together, these observations suggest that glutamate couples synaptic activity to microvascular tone in the cerebellum granular layer by engaging two competing signaling pathways promoting either vasorelaxation (i.e., through NMDARs) or vasoconstriction (i.e., through mGluRs).

\section{Summary and conclusions}

Although most studies have hitherto examined NVC in the molecular layer (Peppiatt et al., 2006; Rancillac et al., 2006; Lauritzen et al., 2012; Hall et al., 2014), herein, we provide evidence that synaptic activation of NMDARs stimulates granular layer neurons to release $\mathrm{NO}$, which in turn vasodilates adjacent capillaries and has the potential to cause a remarkable (up to $23 \%$ ) increase in local CBF. The NO-dependent vasorelaxation overcomes a contrasting vasoconstrictor response mediated by 20-HETE induced by mGluRs that are probably located in non-neuronal cells. Converging evidence suggests that GrCs play a pivotal role in granular layer NVC and this opens an intriguing scenario because these cells are also pivotal to elaborate and store complex spatiotemporal patterns at the MF input (D'Angelo and De Zeeuw, 2009). This may explain the fact that GrCs are NOergic neurons that release $\mathrm{NO}$ both in the granular and molecular layer (D’Angelo, 2014; Bouvier et al., 2016), thus coordinating computational and metabolic functions in the whole cerebellar network. This conclusion remains to be validated in vivo, but it sheds novel light on the hemodynamic response to NA in the cerebellum.

As originally proposed by Diedrichsen et al. (2010) and Howarth et al. (2010), the granular layer regulation of local microvessels could contribute remarkably to shaping cerebellar BOLD signals, which, conversely, proved largely independent from Purkinje cell activity (Thomsen et al., 2004). This observation may provide useful cues for further NVC investigations and cerebellar fMRI analysis.

\section{References}

Akgören N, Fabricius M, Lauritzen M (1994) Importance of nitric oxide for local increases of blood flow in rat cerebellar cortex during electrical stimulation. Proc Natl Acad Sci U S A 91:5903-5907. CrossRef Medline 
Armano S, Rossi P, Taglietti V, D’Angelo E (2000) Long-term potentiation of intrinsic excitability at the mossy fiber-granule cell synapse of rat cerebellum. J Neurosci 20:5208-5216. Medline

Attwell D, Buchan AM, Charpak S, Lauritzen M, Macvicar BA, Newman EA (2010) Glial and neuronal control of brain blood flow. Nature 468:232243. CrossRef Medline

Attwell D, Mishra A, Hall CN, O'Farrell FM, Dalkara T (2016) What is a pericyte? J Cereb Blood Flow Metab 36:451-455. CrossRef Medline

Balcerczyk A, Soszynski M, Bartosz G (2005) On the specificity of 4-amino5-methylamino- $2^{\prime}, 7^{\prime}$-difluorofluorescein as a probe for nitric oxide. Free Radic Biol Med 39:327-335. CrossRef Medline

Batchelor AM, Bartus K, Reynell C, Constantinou S, Halvey EJ, Held KF, Dostmann WR, Vernon J, Garthwaite J (2010) Exquisite sensitivity to subsecond, picomolar nitric oxide transients conferred on cells by guanylyl cyclase-coupled receptors. Proc Natl Acad Sci U S A 107:22060-22065. CrossRef Medline

Bosman LW, Koekkoek SK, Shapiro J, Rijken BF, Zandstra F, van der Ende B, Owens CB, Potters JW, de Gruijl JR, Ruigrok TJ, De Zeeuw CI (2010) Encoding of whisker input by cerebellar Purkinje cells. J Physiol 588: 3757-3783. CrossRef Medline

Bouvier G, Higgins D, Spolidoro M, Carrel D, Mathieu B, Léna C, Dieudonné S, Barbour B, Brunel N, Casado M (2016) Burst-dependent bidirectional plasticity in the cerebellum is driven by presynaptic NMDA receptors. Cell Rep 15:104-116. CrossRef Medline

Busija DW, Bari F, Domoki F, Louis T (2007) Mechanisms involved in the cerebrovascular dilator effects of $\mathrm{N}$-methyl-D-aspartate in cerebral cortex. Brain Res Rev 56:89-100. CrossRef Medline

Caesar K, Thomsen K, Lauritzen M (2003) Dissociation of spikes, synaptic activity, and activity-dependent increments in rat cerebellar blood flow by tonic synaptic inhibition. Proc Natl Acad Sci U S A 100:16000-16005. CrossRef Medline

Cesana E, Pietrajtis K, Bidoret C, Isope P, D’Angelo E, Dieudonné S, Forti L (2013) Granule cell ascending axon excitatory synapses onto Golgi cells implement a potent feedback circuit in the cerebellar granular layer. J Neurosci 33:12430-12446. CrossRef Medline

Chadderton P, Margrie TW, Häusser M (2004) Integration of quanta in cerebellar granule cells during sensory processing. Nature 428:856-860. CrossRef Medline

Cheron G, Márquez-Ruiz J, Dan B (2016) Oscillations, timing, plasticity, and learning in the cerebellum. Cerebellum 15:122-138. CrossRef Medline

Christie JM, Jahr CE (2008) Dendritic NMDA receptors activate axonal calcium channels. Neuron 60:298-307. CrossRef Medline

Dalkara T, Alarcon-Martinez L (2015) Cerebral microvascular pericytes and neurogliovascular signaling in health and disease. Brain Res 1623: 3-17. CrossRef Medline

D'Angelo E (2014) The organization of plasticity in the cerebellar cortex: from synapses to control. Prog Brain Res 210:31-58. CrossRef Medline

D'Angelo E, De Zeeuw CI (2009) Timing and plasticity in the cerebellum: focus on the granular layer. Trends Neurosci 32:30-40. CrossRef Medline

D’Angelo E, De Filippi G, Rossi P, Taglietti V (1995) Synaptic excitation of individual rat cerebellar granule cells in situ: evidence for the role of NMDA receptors. J Physiol 484:397-413. CrossRef Medline

D’Angelo E, Rossi P, Armano S, Taglietti V (1999) Evidence for NMDA and mGlu receptor-dependent long-term potentiation of mossy fiber-granule cell transmission in rat cerebellum. J Neurophysiol 81:277-287. Medline

D’Angelo E, Solinas S, Mapelli J, Gandolfi D, Mapelli L, Prestori F (2013) The cerebellar Golgi cell and spatiotemporal organization of granular layer activity. Front Neural Circuits 7:93. CrossRef Medline

D’Errico A, Prestori F, D'Angelo E (2009) Differential induction of bidirectional long-term changes in neurotransmitter release by frequency-coded patterns at the cerebellar input. J Physiol 587:5843-5857. CrossRef Medline

Diedrichsen J, Verstynen T, Schlerf J, Wiestler T (2010) Advances in functional imaging of the human cerebellum. Curr Opin Neurol 23:382-387. CrossRef Medline

Dillon-Carter O, Chuang DM (1989) Homologous desensitization of muscarinic cholinergic, histaminergic, adrenergic, and serotonergic receptors coupled to phospholipase C in cerebellar granule cells. J Neurochem 52: 598-603. CrossRef Medline

Diwakar S, Lombardo P, Solinas S, Naldi G, D’Angelo E (2011) Local field potential modeling predicts dense activation in cerebellar granule cells clusters under LTP and LTD control. PLoS One 6:e21928. CrossRef Medline

Domoki F, Perciaccante JV, Shimizu K, Puskar M, Busija DW, Bari F (2002) $\mathrm{N}$-methyl-D-aspartate-induced vasodilation is mediated by endotheliumindependent nitric oxide release in piglets. Am J Physiol Heart Circ Physiol 282: H1404-1409. CrossRef Medline

Duchemin S, Boily M, Sadekova N, Girouard H (2012) The complex contribution of NOS interneurons in the physiology of cerebrovascular regulation. Front Neural Circuits 6:51. CrossRef Medline

Dzamba D, Honsa P, Anderova M (2013) NMDA receptors in glial cells: pending questions. Curr Neuropharmacol 11:250-262. CrossRef Medline

Fernández-Klett F, Offenhauser N, Dirnagl U, Priller J, Lindauer U (2010) Pericytes in capillaries are contractile in vivo, but arterioles mediate functional hyperemia in the mouse brain. Proc Natl Acad Sci U S A 107: 22290-22295. CrossRef Medline

Garthwaite J (2016) From synaptically localized to volume transmission by nitric oxide. J Physiol 594:9-18. CrossRef Medline

Garthwaite J, Garthwaite G (1987) Cellular origins of cyclic GMP responses to excitatory amino acid receptor agonists in rat cerebellum in vitro. J Neurochem 48:29-39. CrossRef Medline

Garthwaite J, Garthwaite G, Palmer RM, Moncada S (1989) NMDA receptor activation induces nitric oxide synthesis from arginine in rat brain slices. Eur J Pharmacol 172:413-416. CrossRef Medline

Griffiths C, Wykes V, Bellamy TC, Garthwaite J (2003) A new and simple method for delivering clamped nitric oxide concentrations in the physiological range: application to activation of guanylyl cyclase-coupled nitric oxide receptors. Mol Pharmacol 64:1349-1356. CrossRef Medline

Hall CN, Reynell C, Gesslein B, Hamilton NB, Mishra A, Sutherland BA, O'Farrell FM, Buchan AM, Lauritzen M, Attwell D (2014) Capillary pericytes regulate cerebral blood flow in health and disease. Nature 508: 55-60. CrossRef Medline

Hamilton NB, Attwell D, Hall CN (2010) Pericyte-mediated regulation of capillary diameter: a component of neurovascular coupling in health and disease. Front Neuroenergetics 2.

Herzfeld DJ, Kojima Y, Soetedjo R, Shadmehr R (2015) Encoding of action by the Purkinje cells of the cerebellum. Nature 526:439-442. CrossRef Medline

Hill RA, Tong L, Yuan P, Murikinati S, Gupta S, Grutzendler J (2015) Regional blood flow in the normal and ischemic brain is controlled by arteriolar smooth muscle cell contractility and not by capillary pericytes. Neuron 87:95-110. CrossRef Medline

Hillman EM (2014) Coupling mechanism and significance of the BOLD signal: a status report. Annu Rev Neurosci 37:161-181. CrossRef Medline

Hopper RA, Garthwaite J (2006) Tonic and phasic nitric oxide signals in hippocampal long-term potentiation. J Neurosci 26:11513-11521. CrossRef Medline

Howarth C, Peppiatt-Wildman CM, Attwell D (2010) The energy use associated with neural computation in the cerebellum. J Cereb Blood Flow Metab 30:403-414. CrossRef Medline

Iadecola C (2004) Neurovascular regulation in the normal brain and in Alzheimer's disease. Nat Rev Neurosci 5:347-360. CrossRef Medline

Kolinko Y, Cendelin J, Kralickova M, Tonar Z (2016) Smaller absolute quantities but greater relative densities of microvessels are associated with cerebellar degeneration in Lurcher mice. Front Neuroanat 10:35. CrossRef Medline

Korbo L, Andersen BB, Ladefoged O, Møller A (1993) Total numbers of various cell types in rat cerebellar cortex estimated using an unbiased stereological method. Brain Res 609:262-268. CrossRef Medline

Krueger M, Bechmann I (2010) CNS pericytes: concepts, misconceptions, and a way out. Glia 58:1-10. CrossRef Medline

Lauritzen M, Mathiesen C, Schaefer K, Thomsen KJ (2012) Neuronal inhibition and excitation, and the dichotomic control of brain hemodynamic and oxygen responses. Neuroimage 62:1040-1050. CrossRef Medline

Logothetis NK (2008) What we can do and what we cannot do with fMRI. Nature 453:869-878. CrossRef Medline

Lu K, Clark JW Jr, Ghorbel FH, Robertson CS, Ware DL, Zwischenberger JB, Bidani A (2004) Cerebral autoregulation and gas exchange studied using a human cardiopulmonary model. Am J Physiol Heart Circ Physiol 286:H584-601. CrossRef Medline

Maffei A, Prestori F, Shibuki K, Rossi P, Taglietti V, D’Angelo E (2003) NO enhances presynaptic currents during cerebellar mossy fiber-granule cell LTP. J Neurophysiol 90:2478-2483. CrossRef Medline 
Mapelli L, Rossi P, Nieus T, D’Angelo E (2009) Tonic activation of GABAB receptors reduces release probability at inhibitory connections in the cerebellar glomerulus. J Neurophysiol 101:3089-3099. CrossRef Medline

Mapelli L, Pagani M, Garrido JA, D’Angelo E (2015) Integrated plasticity at inhibitory and excitatory synapses in the cerebellar circuit. Front Cell Neurosci 9.

Mathiesen C, Caesar K, Akgören N, Lauritzen M (1998) Modification of activity-dependent increases of cerebral blood flow by excitatory synaptic activity and spikes in rat cerebellar cortex. J Physiol 512:555-566. CrossRef Medline

Mehta B, Begum G, Joshi NB, Joshi PG (2008) Nitric oxide-mediated modulation of synaptic activity by astrocytic P2Y receptors. J Gen Physiol 132:339-349. CrossRef Medline

Metea MR, Newman EA (2006) Glial cells dilate and constrict blood vessels: a mechanism of neurovascular coupling. J Neurosci 26:2862-2870. CrossRef Medline

Mishra A, O'Farrell FM, Reynell C, Hamilton NB, Hall CN, Attwell D (2014) Imaging pericytes and capillary diameter in brain slices and isolated retinae. Nat Protoc 9:323-336. CrossRef Medline

Monaghan A, Anderson K (1991) Heterogeneity and organizaton of excitatory amino acid receptors and transporters. In: Excitatory amino acids and synaptic function (Wheal HW, Thomson AM, eds), pp 33-54. London: Academic.

Mulligan SJ, MacVicar BA (2004) Calcium transients in astrocyte endfeet cause cerebrovascular constrictions. Nature 431:195-199. CrossRef Medline

Namin SM, Nofallah S, Joshi MS, Kavallieratos K, Tsoukias NM (2013) Kinetic analysis of DAF-FM activation by NO: toward calibration of a NOsensitive fluorescent dye. Nitric Oxide 28:39-46. CrossRef Medline

Peppiatt CM, Howarth C, Mobbs P, Attwell D (2006) Bidirectional control of CNS capillary diameter by pericytes. Nature 443:700-704. CrossRef Medline

Powell K, Mathy A, Duguid I, Häusser M (2015) Synaptic representation of locomotion in single cerebellar granule cells. Elife 4.

Prestori F, Bonardi C, Mapelli L, Lombardo P, Goselink R, De Stefano ME, Gandolfi D, Mapelli J, Bertrand D, Schonewille M, De Zeeuw C, D’Angelo E (2013) Gating of long-term potentiation by nicotinic acetylcholine receptors at the cerebellum input stage. PLoS One 8:e64828. CrossRef Medline

Ramakrishnan KB, Voges K, De Propris L, De Zeeuw CI, D’Angelo E (2016) Tactile stimulation evokes long-lasting potentiation of Purkinje cell discharge in vivo. Front Cell Neurosci 10:36. CrossRef Medline

Rancillac A, Rossier J, Guille M, Tong XK, Geoffroy H, Amatore C, Arbault S, Hamel E, Cauli B (2006) Glutamatergic control of microvascular tone by distinct GABA neurons in the cerebellum. J Neurosci 26:6997-7006. CrossRef Medline

Rancz EA, Ishikawa T, Duguid I, Chadderton P, Mahon S, Häusser M (2007) High-fidelity transmission of sensory information by single cerebellar mossy fibre boutons. Nature 450:1245-1248. CrossRef Medline
Robberechts Q, Wijnants M, Giugliano M, De Schutter E (2010) Long-term depression at parallel fiber to Golgi cell synapses. J Neurophysiol 104: 3413-3423. CrossRef Medline

Sakagami K, Kawamura H, Wu DM, Puro DG (2001) Nitric oxide/cGMPinduced inhibition of calcium and chloride currents in retinal pericytes. Microvasc Res 62:196-203. CrossRef Medline

Salerno JC (2008) Neuronal nitric oxide synthase: prototype for pulsed enzymology. FEBS Lett 582:1395-1399. CrossRef Medline

Salerno JC, Ghosh DK (2009) Space, time and nitric oxide-neuronal nitric oxide synthase generates signal pulses. FEBS J 276:6677-6688. CrossRef Medline

Siero JC, Petridou N, Hoogduin H, Luijten PR, Ramsey NF (2011) Cortical depth-dependent temporal dynamics of the BOLD response in the human brain. J Cereb Blood Flow Metab 31:1999-2008. CrossRef Medline

Siero JC, Ramsey NF, Hoogduin H, Klomp DW, Luijten PR, Petridou N (2013) BOLD specificity and dynamics evaluated in humans at $7 \mathrm{~T}$ : comparing gradient-echo and spin-echo hemodynamic responses. PLoS One 8:e54560. CrossRef Medline

Snyder SH (1992) Nitric oxide: first in a new class of neurotransmitters. Science 257:494-496. CrossRef Medline

Southam E, Morris R, Garthwaite J (1992) Sources and targets of nitric oxide in rat cerebellum. Neurosci Lett 137:241-244. CrossRef Medline

Sweeney MD, Ayyadurai S, Zlokovic BV (2016) Pericytes of the neurovascular unit: key functions and signaling pathways. Nat Neurosci 19:771783. CrossRef Medline

Thomsen K, Offenhauser N, Lauritzen M (2004) Principal neuron spiking: neither necessary nor sufficient for cerebral blood flow in rat cerebellum. J Physiol 560:181-189. CrossRef Medline

Usowicz MM, Gallo V, Cull-Candy SG (1989) Multiple conductance channels in type- 2 cerebellar astrocytes activated by excitatory amino acids. Nature 339:380-383. CrossRef Medline

Wiestler T, McGonigle DJ, Diedrichsen J (2011) Integration of sensory and motor representations of single fingers in the human cerebellum. J Neurophysiol 105:3042-3053. CrossRef Medline

Xu J, Chuang DM (1987) Serotonergic, adrenergic and histaminergic receptors coupled to phospholipase $\mathrm{C}$ in cultured cerebellar granule cells of rats. Biochem Pharmacol 36:2353-2358. CrossRef Medline

Yang G, Iadecola C (1997) Obligatory role of NO in glutamate-dependent hyperemia evoked from cerebellar parallel fibers. Am J Physiol 272: R1155-R1161. Medline

Yang G, Iadecola C (1998) Activation of cerebellar climbing fibers increases cerebellar blood flow: role of glutamate receptors, nitric oxide, and cGMP. Stroke 29:499-507; discussion 507-508. CrossRef Medline

Yang G, Chen G, Ebner TJ, Iadecola C (1999) Nitric oxide is the predominant mediator of cerebellar hyperemia during somatosensory activation in rats. Am J Physiol 277:R1760-R1770. Medline

Zimmermann K (1923) Der feinere Bau der Blutkapillaren. Z Anat Entwicklungsgesch 69:29-109. 